\title{
A Variant of a Regenerative Hydrogen Storage and Production System for Power Installations
}

\author{
Pavel Kudryavtsev* \\ Deputy Director for Research and Development, KUD Industries P. N.Ltd - Israeli Research Center, Israel
}

\begin{abstract}
The aim of this work is to obtain cheap and environmentally friendly fuels for automobile transport, as well as reducing emissions of harmful substances into the atmosphere with car exhaust. The problem can be solved by creating a system for producing technical hydrogen and its use in internal combustion engines and other power units. This article proposed using active metals, their alloys, or metal hydrides interaction with water to generate hydrogen. This proposal is based on an analysis of existing and possible methods of storing and transporting hydrogen. For the practical realization of this approach has been proposed the construction of the device of hydrogen storing and generating for powerful engines and vehicles. The functioning of the recommended equipment is to hydrogen generation by reacting the active metals, or their alloys, or metal hydrides with water in a polar aprotic organic solvent. From these products, it has been proposed to form the cartridges with internal through holes-cartridges placed in the hydrogen generator. The polar solvent pumped through the hydrogen generator in which it reacts with the material of the cartridge. At this solvent is added the water in a controlled manner and used for the reaction with the cartridge material for hydrogen release. Hydrogen, after separation of the liquid phase, flows into the fuel system of the internal combustion engine. The spent solvent is pumped into the solvent intake and storage system and, subsequently, the solvent is replaced when the cartridge is replaced. The system can operate in a closed-loop in the case organization of gathering and recycling of waste materials for reuse.
\end{abstract}

Keywords: Hydrogen, Hydrogen power, Hydrides, Hydrogen storage and generation, Aprotic polar solvents.

\section{Introduction}

Agency "Bloomberg" made a forecast of the development of world energy for the next 25years and it is that "the energy structure of humanity will change forever," and it will happen soon.The essence of the changes can be explained in one phrase: fossil fuels will not withstand competition with renewable energy. First of all, it is solar energy and the issue ultimately rests on the power. ${ }^{1,2}$ The prospect of the exhaustion of hydrocarbon fuels, a large amount of pollution introduced into the environment during the operation of engines based on the combustion of hydrocarbon fuels, determines the relevance of developing technologies that use alternative energy sources. The most promising of these is hydrogen, the oxidation of which releases a large amount of energy and does not produce harmful substances. Hydrogen energy is a developing energy industry that is based on the use of hydrogen as a means of accumulating, transporting and consuming energy by people, the transport infra structure, and various industries. The development of this energy sector is associated, on the one hand, with a decrease in dependence on imported fuel, on the other hand, with requirements for improving the state of the environment. As you know, hydrogen is not found in nature in large quantities in the Free State, but it can be obtained by various technological methods. Firstly, hydrogen can be extracted from natural gas; secondly, it is produced by passing an electric current through water and in a whole number of different ways.

The possibility of large-scale use of hydrogen as an energy carrier determines the need to solve some problems. For example, hydrogen is a secondary source of energy and, therefore, for its production and use requires a developed system of its primary sources. Such sources may be large-scale production of hydrogen carriers. These plants may be similar to the world's petrochemical plants
Quick Response Code:

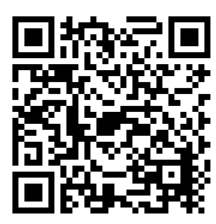

*Corresponding author: Pavel Kudryavtsev, Professor, Deputy Director for Research and Development, KUD Industries P. N.Ltd - Israeli Research Center, Haifa, Israel

Received: 12 January, 2021

Published: 17 February, 2021

Citation: Pavel Kudryavtsev. A Variant of a Regenerative Hydrogen Storage and Production System for Power Installations. Glob Scient Res Env Sci. 2021;1(2):1-8. DOI: 10.53902/GSRES.2021.01.000508 
involved in the processing of fossil fuels. This analogy is because the main production of hydrogen today is concentrated precisely on refineries and petrochemical plants. In this regard, the production of aluminium hydride and cartridges from it can easily fit into the main non-petrochemical production, in the form of detached workshops on the territory of these plants.

The main advantage of hydrogen over organic energy carriers is that carbon dioxide is not released when hydrogen is burned ( $\mathrm{CO}$ and $\mathrm{CO}_{2}$ ). Accordingly, hydrogen less pollutes the atmosphere. Also, hydrogen is beneficial for its use as a fuel for internal combustion engines, since it has higher energy content than any fossil fuel currently used. If you compare the same amount of hydrogen and gasoline, it turns out that the car on hydrogen will be able to drive twice as long as the same amount of gas. ${ }^{3}$ Although the main advantages of hydrogen fuel are clear and beyond doubt, many significant drawbacks should also be noted. Currently, hydrogen fuel cells are still quite expensive. The existing options for devices and methods for the storage and transportation of hydrogen have many significant drawbacks. Thus, when storing hydrogen in a liquid state, it becomes necessary to carry out an expensive liquefaction operation, as well as the use of Dewar's vessels, and losses due to boiling up of hydrogen and the danger of the formation of an explosive detonat- ing mixture are unavoidable. The use of gaseous hydrogen requires its compression to high pressure-about hundreds of atmospheres, necessitating the use of large and durable pressure vessels, which increases the cost of technology and increases the risk of explosion.

Thus, the main problem of hydrogen energy is the problem of storage and transportation of hydrogen. Methods of storing hydrogen for later use to cover a variety of approaches, including high-pressure, cryogenic techniques, and chemical compounds that reversibly release $\mathrm{H}_{2}$ under specific influences.Most researches on hydrogen storage are focused on storing hydrogen in the form of solid compounds-hydrides as light and compact energy sources for mobile applications.Comparison of different methods of hydrogen storage is presented in Figure 1. For practical use of the device for storing and transporting hydrogen, they must be inexpensive, relatively light-weight and safe and, if possible, reusable. Thus, bound hydrogen remains the most promising option for solving the problem of transportation and storage in general. Such hydrogen storage methods for its subsequent use cover many approaches and chemical compounds, which, including reversibly release $\mathrm{H}_{2}$ under specific influences. Most modern hydrogen storage research focuses on hydrogen storage in the form of solid compounds-hydrides, as a lightweight and compact energy carrier for mobile devices. ${ }^{4}$

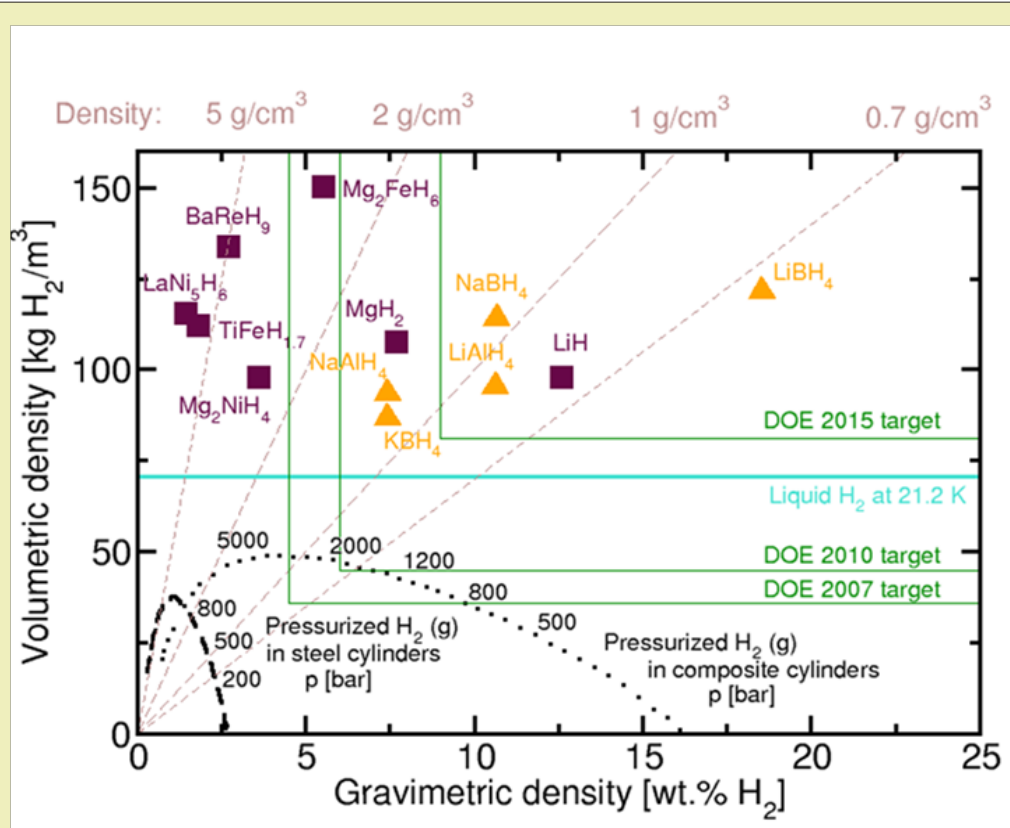

Figure 1: The volume and weight densities of hydrogen at different methods of storage.

All materials capable of storing bound hydrogen can be divided into two types. The first type is materials in which hydrogen is in explicit form and the second is materials containing it implicitly. The second group includes substances capable of reducing hydrogen from water or other chemical compounds as a result of a chemical reaction; a typical example is aluminium and its alloys, alkali metals, etc. Compounds containing hydrogen in explicit form can be divided into three groups, based on the magnitude of the binding energy of an atom or hydrogen molecule with a matrix or other atoms. Physically adsorbed or absorbed hydrogen has the lowest bond strength; a stronger bond is realized in the case of chemisorptions during the formation of hydrogen valence bonds in molecular compounds, ionic binary or ternary metal hydrides, and the third group compounds in which hydrogen is bound to other chemical elements by strong covalent bonds. The most detailed and useful analysis of possible hydrogen storage systems in the form of hydrides was made in. ${ }^{5}$ The first group is of little use, due to the low hydrogen content in such materials. The third group contains the most strongly bound hydrogen, which requires too high energy consumption for its release. Lithium hydride LiH has the higher 
hydrogen content out of other hydrides and more than three times exceeds the content of hydrogen in sodium hydride $\mathrm{NaH}$. The $\mathrm{LiH}$ is of great interest for hydrogen storage, but its resistance to decomposition is an obstacle to practical use. Thus, removal of $\mathrm{H}_{2}$ requires temperatures above $700^{\circ} \mathrm{C}$ needed for its synthesis, and such temperatures are costly to build and maintain. ${ }^{6}$

Metal hydrides such as $\mathrm{MgH}_{2}, \mathrm{NaAlH}_{4}, \mathrm{LiAlH}_{4}, \mathrm{LiH}, \mathrm{LaNi}_{5} \mathrm{H}_{6}$, $\mathrm{TiFeH}_{2}$ and palladium hydride which were used with varying degrees of success, also may be employed as hydrogen storages, often reversible. ${ }^{4}$ These materials have a good energy density in volume, although their weight energy density is often worse than that of the essential hydrocarbon fuels. Most metal hydrides have a powerful bond to hydrogen. As a result, the hydrogen contained therein is released at high temperatures of about $120 \div 200$. The energy costs can be reduced by using mixed compounds, such as in $\mathrm{LiNH}_{2}$, Li$\mathrm{AlH}_{4}$ and $\mathrm{NaBH}_{4}{ }^{7}{ }^{7}$ Metal hydrides are represented by squares and complex hydrides (including $\mathrm{LiAlH}_{4}$ ) by triangles. $\mathrm{BaReH}_{9}$ has the highest known ratio of metal and hydrogen $(\mathrm{H} /(\mathrm{Ba}+\mathrm{Re})=4.5) .{ }^{8} \mathrm{Mg}$ $2 \mathrm{FeH}_{6}$ has the highest known bulk density of $\mathrm{H}_{2}$. $\mathrm{LiBH}_{4}$ has the highest weight density. The values presented for the hydrides exclude the role of capacity. Objectives are DOE, including the weight of the container. $^{9}$

$\mathrm{LiAlH}_{4}$ contains $10.6 \%$ by weight of hydrogen, which makes it a potential hydrogen storage medium for future use in vehicle fuel cells. The high content of hydrogen, as well as finding of the reversible hydrogen storage properties in $\mathrm{NaAlH}_{4}$ doped with titanium ${ }^{10}$ called over the last decade for the resumption of $\mathrm{LiAlH}_{4}$ research. Significant research efforts have been directed to acceleration in decomposition kinetics by catalytic doping and grinding in a ball mill. ${ }^{11}$ To take advantage of the total capacity of the hydrogen, the intermediate $\mathrm{LiH}$ must be dehydrogenated as much as possible. Because of the high thermodynamic stability of the product of hydrogenation, the temperatures should exceed $400^{\circ} \mathrm{C}$, which is not considered feasible for transport purposes. Getting as the final product, a mixture of $\mathrm{LiH}$ and $\mathrm{Al}$ reduces the hydrogen storage capacity to $7.96 \mathrm{wt} . \%$. Another problem associated with hydrogen storage is inverse recirculation of $\mathrm{LiAlH}_{4}$, which, due to its relatively low stability, requires exceptionally high hydrogen pressure above 10,000 bar. $^{11}$

Lithium borohydride $\mathrm{NaBH}_{4}$ is known as one of the chemical energy carriers that has the highest energy density. The high specific energy density of lithium borohydride made it an attractive candidate that can be offered for automotive and rocket fuel, but in-spite of the research and advocacy, it is not yet widely used. Like all energy-based hydrides, lithium borohydride is very complicated for utilization (i.e., recharge) and therefore suffers from low efficiency of energy conversion. At a density of $0.67 \mathrm{~g} / \mathrm{cm}^{3}$, solid lithium borohydride releases $65 \mathrm{MJ} / \mathrm{kg}$ of heat by reaction with oxygen. For comparison, gasoline gives $44 \mathrm{MJ} / \mathrm{kg}$, whereas the liquid hydrogen provides $120 \mathrm{MJ} / \mathrm{kg}$. Thus lithium-ion batteries have power density up to $0.72 \mathrm{MJ} / \mathrm{kg}$, but the efficiency of energy conversion can reach $90 \%$. Because of the complexity in the mechanisms of cyclic use of metal hydrides, such high energy conversion efficiency is beyond the practical reach. However, due to the high energy consumption, their use will probably be in the region schemes of compromise.

As one of the possible ways of developing this direction, the use of active matrices, for example, carbon materials modified with impurity atoms, i.e., transition from the mechanism of physical sorption to the mechanism of chemisorptions. The latter principle is well known from the chemistry of hydride compounds of intermetallic compounds, which are the most studied candidates for use as materials that absorb hydrogen. The main disadvantage that makes these substances unsuitable for practical implementation is the low mass content of hydrogen at a very high density of the inter metallic compound itself ( $1 \mathrm{~kg}$ of gas- $50 \mathrm{~kg}$ of intermetallic compound, with an average filling pressure of $30 \div 40 \mathrm{~atm}$ and an operating pressure of $2 \div 4 \mathrm{~atm})^{5}$

\section{Possible methods of hydrogen storage and production}

Another option for the extraction of hydrogen from various substances is their interaction with water and other liquids containing hydrogen. The use of such schemes allows the removal of hydrogen from different materials at room or even low temperature. Such an approach does not require any severe energy expenditures for the implementation of such a process while expanding the range of substances that can be used for storage and extraction of hydrogen. To implement such an option for storing and producing hydrogen, pure metals, their alloys, and simple hydrides can be used. As the liquid component, you can use water and aqueous solutions of acids and bases. You can also use aqueous-organic solutions containing polar organic liquids, which allows the process of hydrogen evolution not only at room temperatures but also at temperatures below the freezing point of water $<0^{\circ} \mathrm{C}$.

According to the authors of, ${ }^{5}$ the hydrolytic decomposition of binary and ternary hydrides also gives twice the amount of hydrogen compared to thermolysis, although the regeneration of matter remains fundamentally possible, for economic reasons, according to the authors, it becomes inappropriate. Another drawback, in their opinion, of the hydrolytic hydrogen evolution scheme, is the need to use a significant excess of water against the stoichiometry of the reactions, and in some cases, acidic or alkaline media. But such a phenomenon is characteristic of compounds in which hydrogen is very strong bound. There are a large number of compounds that actively interact with water, even with its presence in small quantities.Examples of such systems are classical methods for producing the absolute of alcohols and other anhydrous chemical compounds. According to the authors of, ${ }^{5}$ sodium borohydride $\mathrm{NaBH}_{4}$ is one of the best sources of hydrogen according to the hydrolytic scheme. Here we can partially agree with the opinion of the authors, since this compound, although it contains a large amount of hydrogen in its composition; however, it is persistent and hydrolytically stable. Based on this logic, a compound such as lithium borohydride $\mathrm{LiBH}_{4}$ would be more suitable, but it, having higher specific hydrogen content, is also quite stable concerning hydrolysis.

Nevertheless, we believe that the hydrolytic scheme for producing hydrogen from hydride or pure metal sources has a right 
to exist, and not only in disposable devices or in sea-based devices, but also the widespread practice of operation in the automobile transport and other power plants. Of course, the implementation of this approach requires the creation of specific infrastructure for the production of such compounds and products from them, a system for providing propulsion and power plants with these products for the collection, and processing of used materials for their reuse.Such a system will not differ much from the existing infrastructure for the production and distribution of liquid organic fuel.

An example of such an embodiment of the process of storage and hydrogen evolution is the reaction of lithium hydride with water:

$$
\mathrm{LiH}+\mathrm{H}_{2} \mathrm{O} \rightarrow \mathrm{LiOH}+\mathrm{H}_{2} \uparrow
$$

In this reaction, $1 \mathrm{~kg}$ of lithium hydride can liberate $2.8 \mathrm{~m}^{3}$ of hydrogen. Therefore, lithium hydride has been used for many years as a solid source of hydrogen to fill life-saving appliances, balloons, etc. Thus, lithium hydride and lithium aluminium hydride can easily be used to generate hydrogen by their interaction with water. It can be hoped that their similar use will have excellent prospects in hydrogen energy. ${ }^{4}$ Known methods for producing hydrogen by reacting water with an amalgam of aluminium or a metal selected from the group of beryllium, zirconium, manganese, titanium, chromium at elevated temperatures; ${ }^{12}$ as well as aluminium and gallium, indium, and tin additives; ${ }^{13}$ and alloys containing lithium, sodium or potassium. ${ }^{14}$ For example, by such a reaction:

$$
\mathrm{Al}+\mathrm{H}_{2} \mathrm{O} \rightarrow \mathrm{AlOOH}+\mathrm{H}_{2} \uparrow
$$

The main disadvantages of these methods are the high consumption of expensive alloys and rare metals, their storage in sealed vessels or under a layer of inert gas and the absence of a controlled water supply system for carrying out the hydrogen evolution reaction. In, ${ }^{15}$ a thermo-chemical process was described for producing hydrogen from water, which requires heating to a temperature of $800-1000^{\circ} \mathrm{C}$. The main disadvantages of this method are the availability of an independent heat source, and the need for processing and intermediate storage of hydrogen significantly increases the cost of its practical implementation.

You can use the processes of interaction of metals with acids:

$$
2 \mathrm{Al}+6 \mathrm{HCl} \rightarrow 2 \mathrm{AlCl}_{3}+3 \mathrm{H}_{2} \uparrow
$$

However, the use of acids is associated with their high aggressiveness and corrosiveness, requiring additional equipment protection. Also, acids can be partially removed with hydrogen and transferred to the power plant in the gas phase, where it can also cause corrosion. In the patent, ${ }^{16}$ a hydrogen storage and production scheme is described based on a method for producing dispersed powders of hydride-forming alloys. However, this technical solution does not ensure the effective operation of the internal combustion engine. In, ${ }^{17}$ aluminium hydride $\mathrm{AlH}_{3}$ was shown as a promising material for the storage of $\mathrm{H}_{2}$ for fuel cell systems. Its use offers significant weight savings compared to conventional lithium-ion batteries, due to its high $\mathrm{H}_{2}$ capacity and a simple balance of technical requirements for producing $\mathrm{H}_{2}$. In this work, the authors report on the development and description of the properties of a system of new, portable fuel cells based on $\mathrm{AlH}_{3}$. However, the measured characteristics of the system showed unexpectedly low energy density values, $25 \%$ lower than expected ( $436 \mathrm{~W} \cdot \mathrm{h} \cdot \mathrm{kg}^{-1}$ versus $582 \mathrm{~W} \cdot \mathrm{h} \cdot \mathrm{kg}^{-1}$ ). As it turned out, this phenomenon is associated with incomplete thermolysis of $\alpha$-AlH3. Complete thermolysis was supposed to occur at a temperature of $<180^{\circ} \mathrm{C}$; however, the authors found that it was not achieved, despite the high exposure temperature $\left(>250^{\circ} \mathrm{C}\right)$. This work gives an experimental explanation of this phenomenon and describes it quantitatively by developing a new model within the Avrami-Erofeev phase transformation model, which can be used for the optimal design of $\mathrm{AlH}_{3}$ cartridges with a high energy density. However, these temperature conditions alone are inconvenient for practical use, since they require additional energy consumption to maintain such a temperature.Besides, such temperatures pose a certain danger in conditions of widespread use.

\section{Selection of a hydrogen storage and generation system}

Since the purpose of this work is to obtain shower and environmentally friendly fuel for road transport, as well as to reduce emissions of harmful substances into the atmosphere with exhaust gases from cars, the problem can be solved by creating a system for technical hydrogen production and its use in internal combustion engines and other power units. The proposed system contains a hydrogen generator with a replaceable cartridge containing metal hydride. The hydrogen generator also contains a gas-liquid separator, a tank for circulating solvent, a circulation pump, a water-metering pump, a tank with water and fittings for supplying fresh and removing spent solvent and filling the tank with water.

We analyzed the characteristics of various metals and hydrides of various metals to select the material that will be used in the manufacture of the cartridge for the hydrogen generator. Comparative calculated data on the generation of hydrogen using such systems are presented in Table 1. Based on the energy of burning hydrogen and gasoline, and the average consumption of gasoline per $100 \mathrm{ki}-$ lometers for an average car, you can calculate the rate of hydrogen consumption per 100 kilometers. It averages $1,144 \mathrm{~kg} / 100 \mathrm{~km}$. Thus, the volumetric weight parameters of the cartridges were calculated, which ensure vehicle mileage over a distance of $500 \mathrm{~km}$. From the above table, it can be seen that all of the above products have good hydrogen generation. However, alkali metals, having a high rate of interaction with water, still give the smallest hydrogen generation efficiency. This effect is explained by the fact that these compounds give only one hydrogen molecule per 2reacting metal atoms. Thus, in the case of using metals, the generation of hydrogen strongly depends on the degree of oxidation of the metal in the resulting chemical compound. From this, it is seen that divalent alkaline earth metals give a better generation than monovalent alkaline metals, and trivalent aluminium gives the best generation. Naturally, hydrides, having in their composition additional hydrogen atoms, give even greater hydrogen generation in these processes. Accordingly, complex hydrides $\mathrm{LiAlH}_{4}$ and $\mathrm{NaAlH}_{4}$ give a generation close to hydrides of divalent alkaline earth metals. 
Table 1: Use of metals and metal hydride to the generation of hydrogen by reaction with water.

\begin{tabular}{|c|c|c|c|c|c|c|c|}
\hline $\begin{array}{l}\text { Substance for } \\
\text { the generation } \\
\text { of hydrogen }\end{array}$ & $\begin{array}{l}\text { The density of the } \\
\text { substance for the } \\
\text { generation of hydro- } \\
\text { gen. } \mathrm{g} / \mathrm{cm}^{3}\end{array}$ & $\begin{array}{c}\mathrm{H}_{2} \text { generation. } \\
\text { in } \mathrm{kg} \text {. per } 1 \mathrm{~kg} \\
\text { of the starting } \\
\text { substance }\end{array}$ & $\begin{array}{c}\text { The consumption } \\
\text { rate of the starting } \\
\text { material in kg. per } \\
1 \mathrm{~kg} \text { of } \mathrm{H}_{2}\end{array}$ & $\begin{array}{c}\text { Mileage km } \\
\text { per 1kg of } \\
\text { cartridge sub- } \\
\text { stance } \\
\end{array}$ & $\begin{array}{c}\text { Cartridge } \\
\text { Weight in kg. } \\
\text { for mileage of } \\
500 \mathrm{~km}\end{array}$ & $\begin{array}{c}\text { Cartridge vol- } \\
\text { ume in liters. } \\
\text { for mileage of } \\
500 \mathrm{~km}\end{array}$ & Note \\
\hline $\mathrm{TiH}_{2}$ & 3.72 & 0.121 & 8.25 & 10.6 & 47.2 & 12.69 & $*$ \\
\hline $\mathrm{Al}$ & 2.7 & 0.112 & 8.92 & 9.8 & 51.0 & 18.90 & * \\
\hline $\mathrm{AlH}_{3}$ & 1.45 & 0.202 & 4.96 & 17.6 & 28.4 & 19.57 & \\
\hline $\mathrm{MgH}_{2}$ & 1.419 & 0.153 & 6.53 & 13.4 & 37.3 & 26.31 & \\
\hline $\mathrm{LiH}$ & 0.775 & 0.254 & 3.94 & 22.2 & 22.6 & 29.10 & \\
\hline $\mathrm{LiAlH}_{4}$ & 0.917 & 0.212 & 4.71 & 18.6 & 26.9 & 29.35 & \\
\hline $\mathrm{NaAlH}_{4}$ & 1.28 & 0.149 & 6.70 & 13.1 & 38.3 & 29.92 & \\
\hline $\mathrm{CaH}_{2}$ & 1.7 & 0.096 & 10.44 & 8.4 & 59.7 & 35.12 & \\
\hline $\mathrm{Mg}$ & 1.74 & 0.083 & 12.06 & 7.3 & 69.0 & 39.63 & \\
\hline $\mathrm{NaH}$ & 13.782 & 0.084 & 11.90 & 7.3 & 68.1 & 49.40 & \\
\hline $\mathrm{Li}$ & 0.543 & 0.145 & 6.89 & 12.7 & 39.4 & 72.53 & \\
\hline $\mathrm{Ca}$ & 1.55 & 0.050 & 19.88 & 4.4 & 113.7 & 73.36 & \\
\hline $\mathrm{KH}$ & 1.432 & 0.050 & 19.90 & 4.4 & 113.8 & 79.45 & \\
\hline $\mathrm{Na}$ & 0.971 & 0.0434 & 22.8 & 3.8 & 130.4 & 134.33 & \\
\hline $\mathrm{K}$ & 0.86 & 0.026 & 38.8 & 2.3 & 221.8 & 257.94 & \\
\hline
\end{tabular}

*Need high temperature and passivated surface.

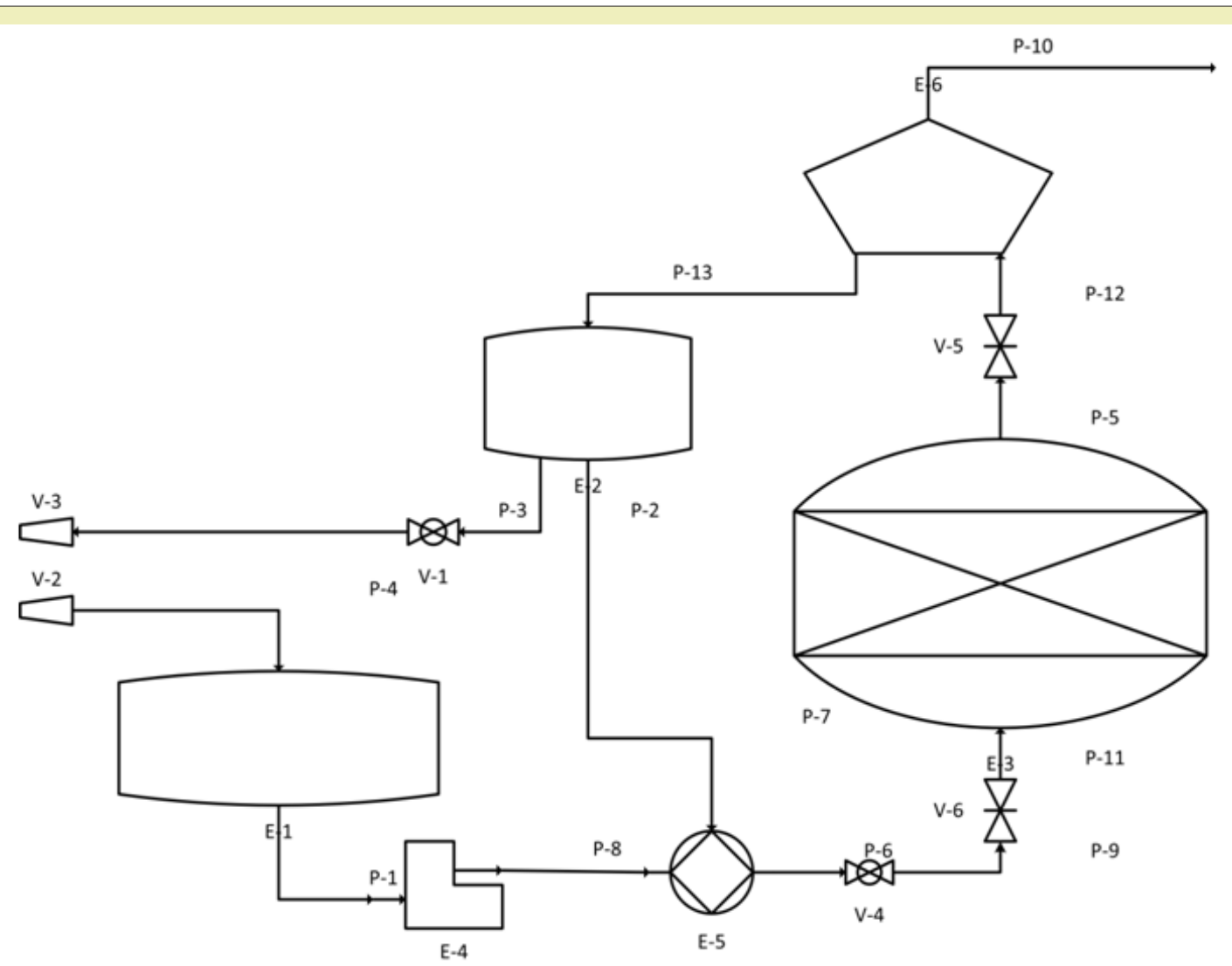

Figure 2: Schematic diagram of the installation for producing hydrogen by contacting the solution of water in a polar organic solvent with a hydride cartridge.E1, water container;E-2, container for polar organic solvent;E-3, replaceable, hydride cartridge;E-4, dosing pump for water;E-5, circulation pump-mixer for water and polar organic solvent; $E-6$, a separator for separating hydrogen from the liquid phase; $V-1,4$, valves for closing and opening system for recharging; $\mathrm{V}-2,3$, fittings for external connection for filling with water and replace the polar organic solvent; $\mathrm{V}-5,6$, bayonet fittings for the cartridgeconnection;P-1-13, system pipelines. 


\section{Design of a hydrogen storage and generation based on aluminium hydride cartridges}

A schematic diagram of a device for implementing the proposed method for producing and using hydrogen is shown in Figure 2. The circuit of the developed device contains the hydrogen generator itself, consisting of a replaceable hydride cartridge (E-3), which is a block with through holes.Hydrogen evolution in the cartridge occurs on the inner surface of the through-holes. The diameter and number of holes in the hydride block of the cartridge are selected based on the required surface area of the cartridge, to ensure the free flow of the organic solvent and prevent it from clogging with reaction products. The structure of this scheme includes a gas-liquid separator (E-6), a tank for a circulating polar organic solvent (E2), a circulation pump (E-5), a water metering pump (E-4), a water tank (E-1) and fittings for connecting the fresh supply and removal of waste solvent, and filling the tank with water (V-5 and V-8). The operation of this device is as follows. The E- 5 circulation pump continuously pumps through the replaceable hydride cartridge E-3 a polar organic solvent. The solvent alone does not interact with the hydride in the cartridge. So is the idle mode of operation of the device.

If the hydrogen generation system starts to work, to ensure the power plant, the E-4 water dispenser is turned on, which starts to supply a controlled amount of water to the E-5 circulation pump, where water and the polar organic solvent are mixed. A solution of water in a polar organic solvent, entering the hydride cartridge E-3, begins to generate hydrogen by the reaction:

$$
\mathrm{AlH}_{3}+3 \mathrm{H}_{2} \mathrm{O} \rightarrow \mathrm{Al}(\mathrm{OH})_{3} \downarrow+3 \mathrm{H}_{2} \uparrow
$$

The evolved hydrogen, together with the polar organic solvent, enters the gas-liquid separator, where hydrogen is separated from the liquid phase and is dried. The hydrogen thus obtained is fed through line P-10 to a power plant for combustion or to a fuel cell for generating electrical energy. The organic solvent, with particles of aluminium hydroxide suspended in it, is fed back to the E-2 tank. Particles of aluminium hydroxide are small in size and form a fairly stable suspension. Partially they are deposited in the tank E-2 and then removed from the system when replacing the organic solvent at the next refuelling. They also do not interfere or clog the hydride cartridge, since it is a block with through holes through which the suspension passes easily. It was experimentally shown that aluminium hydride interaction with water contained in an organic solvent is mainly by a topotaxic mechanism. In this case, the bulk of the aluminium hydroxide remains in the cartridge matrix. However, the removal of aluminium hydroxide particles increases with an increase in the degree of conversion of aluminium hydride. The resulting suspension of aluminium hydroxide is quite stable in the period required to transfer the solvent from the cartridge E-3 to the separator E-6. Also, hydrogen bubbles rising together with the suspension help maintain the suspension aluminium hydroxide particles. The design of the E- 6 separator facilitates the free flow of the solvent suspension into the E-2 tank.

When recharging the system at a gas station, the E-3 hydride cartridge is completely replaced by opening the V-5 and V- 6 bay- onet fittings with the V-4 valve closed. When connected to an external loading system, V-3 fitting unloads the spent polar organic solvent with a suspension of aluminium hydroxide particles and loads fresh solvent. The V-1 valve on the organic solvent tank is in the closed position during system operation, and when the solvent is changed, it opens. The V-2 fitting refills the system with water. The spent suspension of the organic solvent and aluminium hydroxide is sent from the gas station to the processing plant, where the solvent is separated and purified, and the separated aluminium hydroxide is further processed to produce aluminium hydride.Further, blocks are produced from aluminium hydride, which re-equip the replaceable cartridges. It becomes especially necessary for the selection of the solvent. The solvent used must not interact with the hydrides that make up the cartridge, must be mixed with water in unlimited proportions, and must be strongly polar to activate further the interaction of metal hydrides with water. This type of solvent includes aprotic solvents. The aprotic solvent is a chemical compound whose molecules are unable to form hydrogen ions $\mathrm{H}+$ upon dissociation. Among such solvents, a separate group consists of polar aprotic solvents, which retain the ability to dissolve ions but do not contain acid hydrogen. They usually have a high dielectric constant and high polarity. Examples of such solvents are presented in Table 2.

Polar aprotic solvents are usually suitable for carrying out reactions with strong bases, such as Grignard reagent or butyl lithium and quite well; all the solvents indicated in Table 2 can be used in systems for the generation of hydrogen from metal hydrides by their interaction with water. However, the solvents used for this should still have several properties. So they should not be flammable substances, that is, they must have a flash point above $28^{\circ}$. The boiling point of solvents should also not below to prevent their evaporation and to boil in hot weather conditions. Therefore, in our opinion, their boiling point should be equal to or higher than the boiling point of water. For comparison, the flashpoint of high-octane gasoline is $>-20^{\circ}$, and the boiling point starts from $150^{\circ}$. The solvents used should also not have oxidizing properties to prevent their reduction by hydrogen under reaction conditions.

Thus, from Table 2 it is seen that such solvents as THF, 1,4-dioxane, and piperidine are not suitable for use in this device due to their low boiling point; also, these solvents have a rather low dipole moment, which indicates their low polarity. The use of solvents such as DMSO and HMPTA may also be limited due to their high melting point and difficulties in their use in territories with cold climatic conditions. Pyridine is on the verge of acceptable parameters, but it has such a significant drawback as relatively high toxicity. Table 2 also provides toxicity data for this solvents. One of the most widely used hazard indicators for toxic and moderately toxic substances is the $L_{50}$ parameter. $L_{50}$ is the average dose of a substance that causes the death of half of the members of the test group. Moderately toxic substances include those that have an $\mathrm{LD}_{50}$ in the range of $0.151-1.5 \mathrm{~g} / \mathrm{kg}$, low toxic substances with an $\mathrm{LD}_{50}$ of more than $1.5 \mathrm{~g} / \mathrm{kg}$. Table 2 shows the data for mice when taken orally. From these data, it is clear that all of the proposed solvents, except pyridine and partially THF, are low toxic. For comparison, it 
is fashionable to say that table salt has an $\mathrm{LD}_{50}$ of $3 \mathrm{~g} / \mathrm{kg}$. From the above analysis, it follows that the thermal and polar properties of the most suitable solvents are DMFA, DMAA, and NMP. If we compare the toxic features of these solvents, we can see that the $\mathrm{LD}_{50}$ for DMFA and DMAA is $4.2 \mathrm{~g} / \mathrm{kg}$, the NMP solvent with $\mathrm{LD}_{50} 5.2 \mathrm{~g} /$ $\mathrm{kg}$ is less toxic. The proposed approach is quite simple from a tech-

Table 2: Polaraproticsolvents.

\begin{tabular}{|c|c|c|c|c|c|c|}
\hline Name & Density. $\mathrm{g} / \mathrm{cm}^{3}$ & Tmp. ${ }^{\circ} \mathrm{C}$ & Tbp. ${ }^{\circ} \mathrm{C}$ & Tfp. ${ }^{\circ} \mathrm{C}$ & Dipolemoment. D & LD50. g/kg (mouse. oral) ${ }^{18}$ \\
\hline Tetrahydrofuran (THF) & 0.8892 & -108.4 & 66 & -14.5 & 1.63 & 2.3 \\
\hline 1.4-dioxane & 1.033 & 12 & 101 & 5 & 0.0013 & 5.4 \\
\hline Piperidine & 0.862 & -7 & 106 & 16 & 1.15 & 5.0 \\
\hline Pyridine & 0.9818 & -41.6 & 115.2 & 20 & 2.2 & 0.9 \\
\hline N.N-Dimethylformamide (DMFA) & 0.9445 & -61 & 153 & 59 & 3.82 & 4.2 \\
\hline N.N-Dimethylacetamide (DMAA) & 0.9366 & -20 & 165.5 & 70 & 3.8 & 4.2 \\
\hline Dimethylsulfoxide (DMSO) & 1.1004 & 18.5 & 189 & 95 & 3.96 & 20 \\
\hline N-methyl-2-pyrrolidone (NMP) & 1.028 & -24 & 204 & 96 & 4.12 & 5.2 \\
\hline $\begin{array}{l}\text { Hexamethylphosphorictri- } \\
\text { amide(HMPTA) }\end{array}$ & 1.03 & 7.2 & 235 & 122 & 3.96 & 4.2 \\
\hline
\end{tabular}

\section{Conclusion}

The author of this work has analyzed the possible ways of storing and transporting hydrogen. It is proposed to use for the generation of hydrogen the interaction of active metals, or their alloys, or metal hydrides with water. For the practical implementation of this approach, a method for storing and generating hydrogen is proposed, as well as a schematic diagram of a device for storing and generating hydrogen, intended for use in power propulsion systems and cars. The work of this system is to generate hydrogen in the interaction of active metals, or their alloys, or metal hydrides with water in a polar organic solvent. Cartridges with internal through-holes are formed from metals or their alloys or form metal hydrides. Cartridges are placed in a hydrogen generator.A polar aprotic solvent is pumped through the cartridge in a hydrogen generator, which does not interact with the material of the cartridgethis solvent specific as a circulating medium. Water is dosed into this liquid to carry out its reaction with the content of the cartridge and the evolution of hydrogen. A gas-liquid mixture of hydrogen and a polar solvent enters the gas-liquid separator, where hydrogen is separated from the liquid phase. From the separator, hydrogen enters the fuel system of the internal combustion engine. Spent recycled solvent is in the solvent intake and refuelling system, and is replaced when the cartridge is replaced.

The final implementation of this approach will require the creation of specific infrastructure for the production of such compounds and cartridges containing them. It will also be necessary to create a system to provide propulsion and power plants with these products. This system can work in a closed cycle while ensuring the collection and processing of waste materials for their reuse. A similar system will be identical to the existing system for the production and distribution of liquid fossil fuels. The use of this method of producing and using hydrogen allows obtaining cheap and environmentally friendly fuel for automobile transport; reducing atmospheric emissions of harmful substances from car exhaust. nological point of view, easy to manage and safe since the adjustment of the hydrogen output volume is carried out by controlling the amount of water supply to the reactor with a cartridge. In this case, to turn off the reactor, it is enough to turn off the water supply to the system.

\section{Acknowledgments}

None.

\section{Funding}

None.

\section{Conflicts of interest}

Author declares that there is no conflict of interest.

\section{References}

1. Hijikata Tsuneo. Research and Development of International Clean Energy Network Using Hydrogen Energy. International Journal of Hydrogen Energy. 2001;27(2):115-129.

2. The Hydrogen Economy: Opportunities, Costs, Barriers, and R\&D Needs. National Academy of Engineering. Washington, D.C: The National Academies Press. 2004.

3. http://www.tesla-tehnika.biz/vodorodnoe-toplivo-nedostatki.html

4. DOE Metal hydrides. Annual Progress Report. 2015.

5. Bulychev BM, Storozhenko PA. Molecular and ionic metal hydrides as hydrogen sources for power plants. Alternative Energy and Ecology. 2004;4:5-10.

6. Shpil'rayn EE, Yayekimovich KA. Lithium hydride. Physico-chemical and thermal properties, Moscow: Standards Publishing House; 1972. 108 p.

7. Meganne L Christian, Kondo-François Aguey-Zinsou. Core-Shell Strategy Leading to High Reversible Hydrogen Storage Capacity for $\mathrm{NaBH}_{4}$. ACS Nano. 2012;6(9):7739-7751.

8. Vinitsky EA, Muramatsu T, Somayazulu M, Wanene WK, Liu Z, et al. Structural, vibrational, and electronic properties of $\mathrm{BaReH}_{9}$ under pressure. Journal of Physics: Condensed Matter. 2016;28(50):505701.

9. https://en.wikipedia.org/wiki/Lithium_aluminium_hydride

10. Bogdanovic B, Schwickardi M. Ti-Doped Alkali Metal Aluminium Hydrides as Potential Novel Reversible Hydrogen Storage Materials. Journal of Alloys and Compounds. 1997;253(254):1-9.

11. Varin RA, Czujko T, Wronski ZS. Nanomaterials for Solid State Hydrogen Storage. Springer. 2009;338.

12. Brooke W, Bean RA. Metal-water fueled reactor for generating steam and hydrogenus. US Patent N 3.540.854, U.S. Cl. 1970;23-282.

13. Sokol'skiy DV, Kozin LF, Barmin VP, et al. Aluminium-based alloy for the production of hydrogen. Patent USSR N 535364. 1976.

14. Tsoy AD, Asanov UA, Varshavskiy IL, et al. A method for producing hydrogen. Patent USSR N 681674. 1981.

15. Avakov VB, Zinin VI, Shulyakovskiy OB, et al. A method for producing 
and storing hydrogen in autonomous power systems. Patent of Russian Federation N 2192072. 2001.

16. Burnasheva VV, Ganich EA, Kravchenko OV, et al. A process for preparing dispersible powders hydrido-forming alloys. Patent of Russian Federation N 2122925. 1998.
17. Thampan T, Atwater T, Cook $\mathrm{C}$, et al. Hydrogen generation from aluminium hydride for wearable polymer electrolyte membrane fuel cells. International journal of hydrogen energy. 2016;41(22):9402-9409.

18. Lazarev NV, Levina EN. Harmful substances in the industry. Handbook for chemists, engineers, doctors. 1976. 